\title{
Association of infection, blood transfusion and other clinical factors with retinopathy of prematurity (ROP)
}

\author{
S Akter ${ }^{1}$, R Parvin'², B H N Yasmeen ${ }^{3}$, K S Anwar ${ }^{4}$, M M Hossain ${ }^{5}$
}

Dr. Shaheen Akter MD (Paed), FCPS (Neonatology) Associate Professor \& Head NICU, Enam Medical College

2

Dr. Rubiya Parvin

MD (Paed), FCPS (Paed)

MD (Neonatology)

Assistant Professor (Neonatology)

Institute of Child and Mother Health

${ }^{3}$ Dr. B H Nazma Yasmeen MBBS, MCPS, MD (Paed) Associate Professor

Dept. of Paed

Nortern International Medical

College, Dhaka

${ }^{4}$ Dr. Kazi Shabbir Anwar

MBBS, DO (Dhaka)

FPO (Canada)

Paediatric Ophthalmologist

Bangladesh Eye Hospital

5 Prof. Dr M Monir Hossain DCH, MD (Paed), FCPS (Paed) PhD (Neonatology), FRCP ( Glasgow), FRCP (Edin) Professor of Neonatology, BICH Dhaka Shishu Hospital

\section{Correspondence}

Dr. Shaheen Akter MD (Paed), FCPS (Neonatology) Associate Professor \& Head NICU, Enam Medical College shaheenssr7@yahoo.com

\section{Abstract}

Background : In Bangladesh advancement of neonatal care has increased the survival of preterm very low birth weight (VLBW) neonates; thus the incidence of Retinopathy of prematurity (ROP) has also been increased.

Objective : To identify the cases of ROP and to observe the association of birth weight, infection and other clinical factors (recorded during hospital stay) with its occurrence.

Method : This was a prospective observational study at special care baby unit (SCABU) and Intensive care unit of Dhaka Shishu Hospital from July, 2006 to March, 2008 among premature ( 34 weeks) and/or VLBW ( $1500 \mathrm{gm})$ neonates. Neonates who fulfilled the inclusion criteria were followed up daily to record certain clinical factors and features suggestive of sepsis.Infants were divided into "No ROP group" that included newborns without ROP ( $=35)$, and "ROP group" that included newborns with ROP $(n=23)$. Comparative analysis of recorded clinical factors was done between the two groups.

Result : Among the study neonates rate of ROP occurrence is $40 \%$ (23 of 58). VLBW, culture proven septicaemia, mean total hours of oxygen inhalation, mechanical ventilation, cumulative volume of blood transfusion, and intra ventricular hemorrhage (IVH) grade II were significantly related with ROP. Stepwise logistic regression analysis revealed birth weight $[p=.004$, Odds Ratio (OR), .33; Confidence Interval (CI), 0.14 to.436], culture proven septicaemia $(p=.005 ; 0 R$, $4.0 \mathrm{Cl}, 2.50$ to 9.99 ) and cumulative volume of blood transfusion ( $p=.013 ; 0 \mathrm{R}, .43 ; \mathrm{Cl}, .028$ to .653 ) to be most significant factors.

Conclusion : Rate of ROP occurrence in the current study is $40 \%$ and VLBW, culture proven septicaemia and large volume of blood transfusion are significant risk factors.

\section{Introduction}

Retinopathy of prematurity (ROP) is a disease of incomplete retinal vascularization in infants. ${ }^{1}$ It has been considered as one of the major causes of blindness in infants and children in developed countries. It is now emerging as a problem in developing countries like ours also, due to the increased survival of premature and very low birth weight neonates with the blessings of modern advances in neonatology. ${ }^{2}$

Many recent studies have suggested causative association of low birth weight, low gestational age, high oxygen exposure, blood transfusion and many other factors with ROP. ${ }^{3}$ It has also been found that infections, culture proven septicaemia and associated systemic inflammatory response are also responsible for ROP occurrence. ${ }^{4}$

Neonatal intensive care units (NICU) in developing countries have to face the giant problem of infection and septicaemia among premature infants despite of considerable progress in hygiene and introduction of new antimicrobial agents. ${ }^{5}$ In a study of neonatal sepsis in NICU of the largest pediatric hospital, it has been found that $21 \%$ of neonates with a birth weight less than 1500 grams had septicaemia. ${ }^{6}$ The correlation of septicaemia and other factors with occurrence of ROP in our set up, has yet not been observed.

The purpose of this study is to determine the association of gestational age, birth weight, septicaemia, and other factors with the development of ROP.

\section{Methods}

This prospective observational study has been conducted at Special Care Baby Unit (SCABU) and Intensive Care Unit (ICU) of Dhaka Shishu Hospital (DSH) from $1^{\text {st }}$ July, 2006 to March, 2008. Neonates admitted to SCABU or ICU born at 34 or less weeks of gestation having birth weight $1500 \mathrm{gm}$ were initially enrolled in the study. Neonates who died during hospital stay or could not complete the ophthalmoscope examination schedule were excluded during final data entry. Ophthalmological examinations were performed at Paediatric Ophthalmology Department of Bangladesh Eye Hospital.

At admission maternal history has been recorded from maternal recall and accompanying documents. Duration of gestation has been confirmed by assessing modified new Ballard score. Daily follow up has been documented regarding clinical course, investigations and culture reports if there was any. When the baby got oxygen inhalation its duration, maximum $\mathrm{FiO}_{2}$ (Oxygen fraction of the inspired air, according to Guha $\mathrm{DK}^{7}$ ), highest $\mathrm{SpO}_{2}$ (percent saturation of hemoglobin) was recorded daily.

Based on the presence of one or more clinical signs consistent with possible serious bacterial infection (including lethargy, feeding intolerance, abdominal distension, vomiting, groaning, respiratory distress, hypothermia, hyperthermia) neonates were diagnosed as suspected sepsis. Blood culture was taken in all 
cases of suspected sepsis and cerebrospinal fluid (CSF) culture was performed in cases of suspected meningitis.

Blood was collected aseptically in a standard method. Using a sterile syringe and needle about $2 \mathrm{ml}$ of blood was collected from a peripheral vein and was added to the culture media bottle supplied from the microbiology department.

According to the age of onset of clinical features study neonates were categorized as having early onset neonatal sepsis (EONS) (within 7 days of life) or late onset neonatal sepsis (LONS) (8 to 28 days of life). Daily clinical care was performed by attending neonatologist in accordance with hospital protocol.

At the end of the hospital stay all the parents were counseled for regular follow up and ophthalmological examination. First eye examination date was fixed at 4 to 6 weeks of chronological age of the baby.

One paediatric ophthalmologist has examined all the cases. After initial ophthalmological examination, neonates were advised for repeat examinations. Healthy eyes were examined 2-3 weeks interval, and diseased eyes were examined weekly After ophthalmological examinations neonates were divided into 'No ROP group' that had normal findings on examinations (No ROP) and 'ROP group' that included newborns with abnormal findings (any stages of ROP). Risk factors were compared between the two groups.

\section{Procedure of eye examination}

The ophthalmologist performed indirect ophthalmoscope. Pupils were made dilated with $1 \%$ phenylephrine and $0.5 \%$ tropicamide eye drop. Drops were instilled twice 1 to 5 minutes apart. The examination was performed about 20 to 25 minutes later using a binocular indirect opthalmoscope and $+20 \mathrm{D}$ lense. Lid speculum was used to view the retina properly.

\section{Data analysis}

Data managment and anlaysis was done using the Statistical Package for the Social Science (SPSS, version: 12). Comparative analysis of the variables was done between the "No ROP" and "ROP" groups. During univariate analysis the categorical variable were tested with Chi squire $\left(c^{2}\right)$ and for continuous variables "Student's t test" was done. Multivariate analysis (of the variables which were found to be significantly related with the occurrence of ROP) was done by Stepwise logistic regression analysis.

\section{Ethical approval}

The Thesis and Dissertation Approval Committee, Bangladesh College of Physicians and Surgeons, approved the study. The parents were informed about the study, and their written informed consents were recorded.

\section{Results}

During the study period, 129 premature neonates fulfilled inclusion criteria of which $36(28 \%)$ died. Screening could be completed in 58 neonates (from discharged 93, 62\%). Among 58, "No ROP" group comprised of $35(60 \%)$ and "ROP" group comprised of $23(40 \%)$ neonates (Fig.1). Therefore in this study the rate of ROP occurrence is $40 \%$.

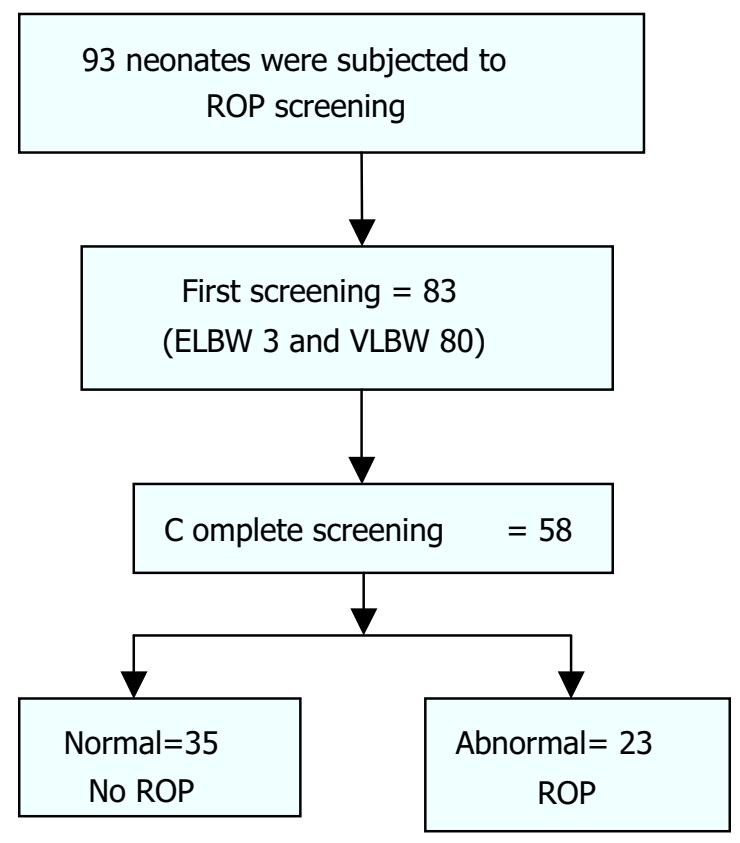

Fig 1: Study population

Characteristics of study neonates have been shown in table I. Among the study population, gestational age was ranging from 27 to 34 weeks and birth weight was ranging from 990 to $1500 \mathrm{gm}$. Twenty six percent of the neonates were delivered at home, $64 \%$ were delivered normally (NVD). Sixty percent of the neonates were admitted within 24 hours of age.

Table I : Distribution of the baseline characteristics among the study neonates $(\mathbf{N}=\mathbf{5 8})$

\begin{tabular}{|c|c|c|c|c|}
\hline Parameters & Categories & Number & Percentage & Mean \\
\hline \multirow{4}{*}{$\begin{array}{l}\text { Ges tational } \\
\text { age(weeks) }\end{array}$} & $27-28$ & 03 & 05 & \multirow[t]{4}{*}{30} \\
\hline & $29-30$ & 19 & 33 & \\
\hline & $31-32$ & 23 & 40 & \\
\hline & $33-34$ & 13 & 22 & \\
\hline \multirow{3}{*}{$\begin{array}{c}\text { Birth } \\
\text { weight } \\
\text { (grams) }\end{array}$} & ?999 & 03 & 06 & \multirow{3}{*}{$1185 \pm 186$} \\
\hline & $1000-1250$ & 17 & 30 & \\
\hline & $1251-1500$ & 38 & 64 & \\
\hline \multirow{2}{*}{$\begin{array}{l}\text { Place of } \\
\text { delivery }\end{array}$} & Hospital & 43 & 74 & \\
\hline & Home & 15 & 26 & \\
\hline \multirow{2}{*}{$\begin{array}{l}\text { Mode of } \\
\text { delivery }\end{array}$} & NVD & 38 & 64 & \\
\hline & LUCS & 20 & 36 & \\
\hline Sex & Male & 28 & 48 & \\
\hline
\end{tabular}

NVD-Normal vaginal delivery LUCS-Lower Uterine caeserian section

In this study suspected bacterial infection cases were 47. Among them 20 babies were in No ROP group and 27 were in ROP group. The most common clinical presentations of patients with suspected bacterial infection were feeding intolarence, (39/47), lethargy (32/47), fluctuation of $\mathrm{SpO}_{2}(13 / 47)$ and colour change (12/47) showed in table II. Of the 47 neonates' with suspected septicaemia $21(45 \%)$ had culture positive septicaemia . Among 21 culture positive septicaemia 6 
had EONS and the rest had LONS. Organisms revealed on blood culture have been narrated in table III. Commonest organism isolated form blood were Acinetobactor (12.7\%), Klebsiella pneumoniae (11\%), Serratia mercesence (8.5\%), Escheriricia coli (8.5\%) and Staphylococcus aureus (4.2\%). None of the CSF culture was positive.

Table II : Clinical features in suspected sepsis cases $(n=47)$

\begin{tabular}{|c|c|c|}
\hline Clinical features & Number & percentage \\
\hline Feeding intolerance & 39 & 83 \\
\hline Lethargy & 32 & 68 \\
\hline Fluctuation of SpO2 & 13 & 28 \\
\hline Color change/mottling & 12 & 25 \\
\hline Apnoe a & 08 & 17 \\
\hline Abdominal distension & 08 & 17 \\
\hline Vomiting & 07 & 15 \\
\hline Convulsion & 07 & 15 \\
\hline Respiratory distress & 06 & 13 \\
\hline Fever & 04 & 09 \\
\hline Hypothermia & 03 & 06 \\
\hline
\end{tabular}

Table III : Organisms isolated on blood, CSF or other cultures $(\mathrm{N}=47)$

\begin{tabular}{|c|c|c|}
\hline Organism & Number & Percentage \\
\hline Acinetobacter & 06 & 13 \\
\hline Klebsiella Pneumoniae & 05 & 11 \\
\hline Serratia marcescence & 04 & 8.5 \\
\hline Escheriricia coli & 04 & 8.5 \\
\hline Staphylococcus aureous & 02 & 4.0 \\
\hline None & 26 & 55 \\
\hline Total & 47 & 100 \\
\hline
\end{tabular}

An univariate analysis was done to see the relationship between investigated risk factors and No ROP and ROP groups. Among eleven risk factors, six were significantly related with the development of ROP (birth weight, culture proven septicaemia, total hours of oxygen inhalation, mechanical ventilation, volume of blood transfusion and IVH) (table IV). Logistic regression analysis showed three of them to be mostly significant. These are very low birth weight, culture proven septicaemia and large cumulative volume of blood transfusion (table V).

Table IV : Univariate analysis on association of risk factors with Ohthamoscopy findings $(\mathrm{N}=58)$

\begin{tabular}{|c|c|c|c|c|}
\hline \multicolumn{1}{|c|}{ Parameters } & $\begin{array}{c}\text { No } \\
\text { ROP(35) }\end{array}$ & ROP(23) & $\begin{array}{l}\text { P } \\
\text { value }\end{array}$ & $\begin{array}{l}\text { Odds ratio(95\% } \\
\text { CI) }\end{array}$ \\
\hline Mean gestational age(weeks) & $30 \pm 2$ & $29 \pm 2$ & .329 & - \\
\hline Mean birth weight(gm) & 1258 & 1070 & .03 & $2.18(1,12-5.95)$ \\
\hline Mother had PET (11) & 06 & 05 & .573 & - \\
\hline Delivered by NVD (39) & 20 & 19 & .266 & - \\
\hline Mal e/Female & $17 / 18$ & $11 / 12$ & 1.00 & \\
\hline Mean hour of 0 2inhalation & 54.54 & 141.41 & .001 & $10.2(4.85-17.82)$ \\
\hline Mechanical ventilation(06) & 0 & 06 & .001 & $3.36(2.05-5.52)$ \\
\hline Suspected septicaemia (47) & 20 & 27 & .243 & - \\
\hline $\begin{array}{c}\text { Culture positive } \\
\text { septicaemia(21) }\end{array}$ & 05 & 16 & .005 & $.05(.010-248)$ \\
\hline Blood tra nsfusion (m/ $/ \mathrm{kg})$ & 10.96 & 67.94 & .005 & $2.79(1.65-4.41)$ \\
\hline IVH grade II or more (12) & 02 & 10 & .08 & $3.75(2.794-7.72)$ \\
\hline
\end{tabular}

Table V: Risk factors revealed in stepwise logistic regression analysis

\begin{tabular}{|c|c|c|c|}
\hline Factors & $p$ value & OR & $95 \% \mathrm{CI}$ \\
\hline Birth weight & .004 & 0.33 & $0.14-.436$ \\
\hline Culture positive septicaemia & .005 & 4.0 & $2.50-9.99$ \\
\hline Blood volume transfused & .013 & 0.43 & $0.028-.653$ \\
\hline
\end{tabular}

\section{Discussion}

This prospective hospital based study identified the ROP cases and associated risk factors among the hospitalized preterm VLBW neonates. ROP has a well-known variation in the incidence as well as in associated risk factors among centers and among countries, related to differences in case ascertainment, sampling variability, and aspects of both obstetric and neonatal clinical practice. ${ }^{2,4,8}$

The same variables have been occasionally reported as associated with an increased risk of ROP by some single-centre, cohort studies, or on the contrary as not associated or even protective by some others. For example, many studies have confirmed the association of Oxygen supplementation with occurence of ROP. ${ }^{2,4}$ On the contrary Shohat M et $\mathrm{al}^{9}$ and Patil J et $\mathrm{al}^{10}$ in their study did not demonstrate any significant association between ROP and length of time in supplemental oxygen or the mean maximum oxygen concentration required. Again, Gitalisa et al ${ }^{11}$ showed that younger gestational age and low birth weight were not associated with the risk of ROP.

Among other risk factors studied, birth weight has been termed as the most significant sign of maturity. ${ }^{12}$ The immaturity of retinal vessel correlate with birth weight. ${ }^{10,13} \mathrm{~A}$ good number of studies have proven the relationship between very low birth weight and occurrence of ROP. $^{2,4,9}$ This study demonstrated the increased incidence of ROP in very low-birth weight babies which is comparable with most studies. Mean birth weight in the ROP group was $1070 \mathrm{gm}$ where as in the normal findings group it was $1258 \mathrm{gm}(\mathrm{p}=.03$; OR , 2.18; $95 \%$ CI $1.12-$ 5.95). Bassiouny et $\mathrm{al}^{3}$ in Indonesia and Shah et $\mathrm{al}^{14}$ had similar findings of mean birth weight.

Though many studies of ROP2,12,14 have shown that younger gestational age has a causative relationship with development of ROP, this study could not reveal any significant relationship. In this study mean gestational age of ROP group was $29.0 \pm 2$ weeks and No ROP group was $30 \pm 2$ weeks. Only $03(05 \%)$ neonates were in the high risk gestational age group ( $<28$ weeks) and $62 \%$ of the neonates had $>30$ weeks of gestation. Unlike developed countries only few very premature extremely low birth weight neonate could be saved who fortunately had a smooth clinical course and short duration of hospital stay. These factors may be responsible for gestational age not to be significant. There are other studies in developing countries who did not find significant relationship between gestational age and ROP. ${ }^{9,11,15}$ Gitallisa et $\mathrm{al}^{11}$ in Indonesia have found that mean gestational age in Normal and ROP group is 33.3 and 32.0 weeks consecutively. Lam et $\mathrm{al}^{15}$ in their study at Hong Kong also could not show the relationship of younger gestational age and ROP.

Infections and sepsis are frequent complications among preterm infants. ${ }^{2-3,8-11}$ Many previous studies of ROP have suggested sepsis as a risk factor. Bacterial, fungal and any other (non-specified) sepsis are significant risk factors in preterm newborns, both for threshold and all 
degrees of ROP. ${ }^{2,16,17}$ Sepsis is frequently accompanied by hypotension, which may impair tissue perfusion and release of angiogenic factors secondary to hypoxic stress. Part of this effect might be due to direct exposure of the developing retina to circulating products of infection and/or inflammation. Another potential mechanism that deserves exploration is that inflammation and/or oxidative stress can modify the known increased risk of oxygen-associated ROP. Taken together, accumulating evidence suggests that prenatal, perinatal, and postnatal systemic inflammation contribute to the occurrence of ROP. ${ }^{4,18}$

In the present study, of 21 culture positive septicaemic neonates, 16 had abnormal retinal examination. Suspected sepsis or culture negative sepsis did not show significant correlation. In premature neonates many diseases are manifested with the features of sepsis. All suspected sepsis with differential diagnoses might not be case of septicaemia till last. This may be the explanation why only the culture proven sepsis became significant. This finding has similarity to that of Bassiouny et al ${ }^{3}$ and Minghua et $\mathrm{al}^{16}$.

Like other studies of ROP, our study revealed prolong duration of oxygen inhalation were significantly associated with abnormal eye examination findings. We had $8(11.1 \%)$ neonates who got mechanical ventilation support and eight of them developed at least stage II- ROP. Bassiony et $\mathrm{al}^{3}$,Shah et $\mathrm{al}^{14}$, Lam et $\mathrm{al}^{15}$ and Minghua et $\mathrm{al}^{16}$ have got the similar result.

Transfusion may adversely influence the retina, not only by increasing oxygen delivery to the retina by adult hemoglobin, but also by overloading iron, which in turn increases free oxygen radicals. ${ }^{18}$ In our study we found $>37 \mathrm{ml} / \mathrm{kg}$ of cumulative blood transfusion has significant association with causation of ROP. We had two neonates who undergone double volume exchange transfusion and both of them developed significant ROP. The authors in their previous report Dani $\mathrm{C}$ et $\mathrm{al}^{19}$ and Dutta et al. $^{20}$ observed that administration of packed cell and double volume exchange transfusions in the neonatal period is a major risk factors for the development of threshold ROP.

\section{Conclusion}

Our study demonstrates the incidence of ROP in low-birth weight babies which is comparable with most Western reports.

The data of our study showed that culture proven septicaemia, very low birth weight and blood transfusion are independent risk factors in the development of ROP. Further prospective and multicentre studies are needed to estimate the true incidence and risk factors of ROP in Bangladesh

\section{References}

1. International Committee for the Classification of Retinopathy of Prematurity: An international classification of retinopathy of prematurity II. The classification of retinal detachment. Arch Ophthalmol 1987; 105: 906- 12

2. Charan $R$, Dogra MR, Gupta $A$, Narang A. The incidence of retinopathy of prematurity in a neonatal care unit. Indian J Ophthalmol 1995; 43:123- 26.

3. Bassiouny MR. Risk factors associated with retinopathy of prematurity: A study from Oman. J Trop Pediatr 1996; 42: 355-58.

4. Lee J, Damman O. Perinatal infection, inflammation, and retinopathy of prematurity. Semin Fetal Neonatal Med. $2012 ; 17: 26-29$.

5. Gotoff SP. Neonatal sepsis and meningitis: In: Nelson Textbook of Pediatrics (18 th Edition). Eds Behrman RE, Kleigman RM, Arvin AM. Philadelphia, WB Saunders
Company, 2008; pp. 528-37.

6. Ahmed ASMNU, Chowdhury MAKA, Hoque M, Darmstadt GL. Clinical and bacteriological profile of neonatal septicemia in a tertiary level pediatric hospital in Bangladesh. Indian Pediatr 2002; 39:1034-39

7. Guha DK, Guha R, Srivastava RD, editors. Manual of newborn critical care medicine1st ed. New Delhi: Jaypee Brothers Medical Publishers; 2006

8. Manjoni P, Farina D, Maestri A, Giovannozzi C, Leonessa ML, Arisio R et al. Mode of delivery and threshold retinpathy of prematurity in preterm ELBW neonates. Acta Pediatrica 2007; 96: 221-26.

9. Shohat M, Resiner SH, Krikler R, Nissenkorn I, Yassur Y, Ben-Sira I. Retinopathy of prematurity : incidence and risk factors. Pediatr. 1983: 72; 159-63.

10. Patil J, Deodhar J, Wagh S, Pandit AN. High risk factors for development of retinopathy of prematurity. Indian Pediatr 1997; 34: 1024-27.

11. Gitalisa AA, Elvioza, RS Sitorus. Screening for retinopathy of prematurity at Cipto Mangunkusumo Hospital, Jakarta, Indonesia -a preliminary report. Acta Medica Lituanica 2006:13:165-70.

12. Brian AD, Jolie LH, David JHS, Deborah AD, Judy MS, Nicholas JE. Prenatal risk factors for severe retinopahty of prematurity among very preterm infants of Australian and New Zealand neonatal network. Pediatr 2005; 115:990-96.

13. Earl AP, Arnall $P$, Dale LP, Rand S. Retinopathy of prematurity. In: Andrew PS, editor. Retina. $3^{\text {rd }}$ ed. Messoouri: Mosby 2001: 1472-79.

14. Shah VA, Yeo CL, Ling YLF, Ho LY. Incidence, risk factors of retinopathy of prematurity among very low birth weight infant in Singapore. Ann Acad Med Singapore 2005; 34:169- 78.

15. Lam BCC, Wong KY, Ng YK, Leung CW, Hui SP, Yeung CY. Retinopathy of Prematurity: Incidence and Perinatal Risk Factors. HK J Paediatr 1998;3:127-30.

16. Minghua C. Ayse C, Frank McC, Katherine ML John F, Christiane E.L.D, Olaf D. Infection, Oxygen, and Immaturity: Interacting Risk Factors for Retinopathy of Prematurity. Neonatol 2011; 99:125-132

17. Kim TI, Sohn J, Pi SY, Yoon YH. Postnatal risk factors for ROP. Paediatr Perinatal Epidemiol 2004; 18: 130-34.

18. Smith LEH. Pathogenesis of ROP. Acta Pediatrica Suppl 2002; 437: 26-28

19. Dani C, Reali MF, Bertini G. The role of blood transfusions and iron intake on retinopathy of prematurity. Early Hum Dev 2001; 62: 57-63.

20. Dutta S, Narang S, Narang A, Gogra M, Gupta A. Risk factors for threshold retinopathy of prematurity. Indian Pediatr 2004; 41: 665-71. 